\title{
ÉPICA, VIOLENCIA Y CONQUISTA EN \\ LOS ACTOS Y HAZAÑAS VALEROSAS DEL CAPITÁN \\ DIEGO HERNÁNDEZ DE SERPA (1564) \\ DE PEDRO DE LA CADENA
}

\section{Raúl Marrero-Fente University of Minnesota}

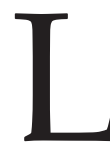

a atención de la crítica se ha centrado en La Araucana (1ra. parte, 1569) de Alonso de Ercilla, calificada como poema fundacional (Pierce 1-37). Este silencio excluyó de la historia literaria obras como Los actos y hazañas valerosas del capitán Diego Hernández de Serpa de Pedro de la Cadena (1564), poema épico breve sobre la conquista de las regiones orientales de la moderna Venezuela.

Las crónicas rimadas de finales del siglo XIV son el antecedente inmediato del poema de Pedro de la Cadena. Esta poesía narrativa de perfil heroico, conocida como "nueva épica", difiere de la épica medieval por el uso de la copla de arte mayor, en respuesta a la cuaderna vía, tanto como por su interés en la historia reciente, en contraste con la vertiente poética que enaltecía los hechos de un pasado remoto (Vaquero 45-63). Uno de los ejemplos más destacados de este grupo de textos es el Poema de Alfonso XI de Rodrigo Yáñez (1348), crónica rimada que celebra la Reconquista. Otra obra representativa de esta nueva épica es la Consolatoria de Castilla de Juan Barba (1487), poema de alabanza a los Reyes Católicos. A esta innovadora modalidad poética también pertenecen textos como el Panegírico en alabanza de la reyna Isabel de Diego Guillén de Ávila (1499), la Vida rimada de Fernán González (ca. 1498) de Gonzalo de Arredondo, la Ystorias de la divinal victoria y nueva adquisición de la muy insigne ciudad de Orán de Martín de Herrera (1511), la Historia Partenopea de Alonso Hernández (1512) y la Práctica de las virtudes de los buenos reyes d'España de Francisco de Castilla (1517), entre otros (Cátedra 1-25).

CALÍOPE Vol.16, No. 1, 2010: pages 61-72 
La poesía escrita a partir de la conquista de América debe estudiarse en este contexto literario porque los poemas americanos no surgen en un vacío cultural. Por otra parte, es importante aclarar que la reacción frente a la naturaleza y a los habitantes de América dejaron una profunda huella en la poesía escrita por los conquistadores. En este panorama histórico y cultural aparece Los actos y hazañas valerosas del capitán Diego Hernández de Serpa de Pedro de la Cadena, un poema épico de 1, 051 versos escritos en endecasílabos sueltos. Cada "acto" o sección del poema comienza con una estrofa de cuatro versos; otras de cinco versos endecasílabos igualmente sin rima cuentan lo ocurrido. Los diecisiete "actos" del poema se cierran arbitrariaments con un verso, o grupos de dos, cuatro o cinco versos.

\section{El manuscrito y la primera edición}

El manuscrito del poema de 25 folios aparece en un volumen de Varios en la Biblioteca de El Escorial bajo la signatura Varios, Diij-25, folios 221-246. Marcelino Menéndez Pelayo mencionó por primera vez la existencia del mismo en la Historia de la poesía hispanoamericana, pero sus comentarios fueron negativos pues afirmó que el poema estaba escrito "en versos sueltos, o más bien en prosa vil" (68). Seguramente esta adversa recepción inicial no despertó interés en Los actos y hazañas, e influyó en la ausencia de ediciones y estudios sobre la obra.

La primera edición del poema apareció en 1973, inserta en el libro El primer poema de tema venezolano, de Pablo Ojer y Efraín Subero. El objetivo de ambos autores es dar a conocer el texto de Pedro de la Cadena y valorar su importancia dentro de la literatura colonial de Venezuela. La edición va acompañada de dos estudios: "Aspectos históricos del primer poema de tema venezolano" de Pablo Ojer donde éste analiza el marco histórico y geográfico de la obra; la polémica en torno a la importancia del poema; la biografía del autor y del protagonista. También estudia la cuestión de la historicidad del Acto VI sobre el ataque a Ingenios, un poblado en el territorio de la moderna Venezuela, y del Acto VII, dedicado a la guerra contra los caribes. En el segundo ensayo, "Aspectos literarios del primer poema de tema venezolano", Efraín Subero examina el panorama de la literatura 
folclórica aborigen y africana en Venezuela. También se ocupa del poema de Pedro de la Cadena a partir de su ubicación en el tiempo y en el espacio: comenta la estructura y estilo de la obra; ofrece un análisis de sus temas principales; y concluye con una valoración crítica. El libro además incluye siete apéndices sobre el proceso de formación de la nacionalidad venezolana a partir de las crónicas coloniales y la literatura folclórica, y del testimonio de viajeros, lingüistas, indígenas $\mathrm{y}$ africanos.

La edición de Ojer y Subero tiene el mérito de rescatar el poema del olvido, estableciendo por primera vez un criterio de edición a partir de un estudio histórico y filológico del texto. Los editores adoptan una modernización ortográfica y aclaran pasajes oscuros del manuscrito. La tarea principal de las ediciones futuras será anotar con más cuidado el texto y hacer un análisis de la métrica del poema que permita revalorizar la importancia de esta vertiente poética en el panorama de la poesía coetánea.

\section{Elautor}

Pedro de la Cadena nació en 1542 en Piedrahita de Ávila, España. Viajó con sus padres al virreinato del Perú en 1556; dos años después se asienta en la ciudad de Cuenca, actual Ecuador. En 1563 fue nombrado Tesorero de la Real Hacienda en Nueva Zamora de los Alcaides, en la zona sur de Ecuador. Al año siguiente figura como testigo en la información de méritos y servicios de Diego Hernández de Serpa, época en la que redactó el poema. Tres años más tarde se alista en expediciones contra los indígenas sublevados de Valladolid; por su participación en estas lides se le recompensa con una encomienda. En 1583 fue nombrado Capitán general de la ciudad de Loja. Un año después asume el cargo de Teniente de Corregidor y Justicia Mayor de la misma ciudad. Participa como alférez en la defensa de la costa ante los ataques de la flota inglesa del comodoro Thomas Cavendish. En 1592 combate contra el levantamiento de las alcabalas en Quito. Siete años más tarde recibe el nombramiento de capitán de una expedición en defensa del Callao. En 1603 es confirmado como Teniente de Corregidor de Loja y Zamora. Tres años después figura como Tesorero de Loja, y en 1607 actúa como Justicia Mayor en la 
misma ciudad. Se desconoce la fecha de su muerte (Ojer y Subero 11727). También fue autor de un tratado inédito de administración colonial que envió al Consejo de Indias (Menéndez Pelayo 69).

\section{El protagonista}

Diego Hernández de Serpa nació en 1510 en Palos de Moguer, España. Viajó a América con su familia hacia 1524. Acompañó a Diego de Ordaz en la expedición por el Orinoco en 1531. Cuatro años más tarde reside en Santa Marta, y en 1539 pasa a Quito. En 1544 se traslada a Panamá y luego viaja a España. Dos años después regresa a América en la flota del virrey del Perú, Pedro de la Gasca, como parte de las tropas que combaten la sublevación de Gonzalo Pizarro en esa zona. En 1549 recibe autorización de la Audiencia de Santo Domingo para la conquista de Guayana, pero ésta es revocada. Reside un tiempo en la isla de Margarita donde es nombrado Alcalde Ordinario y Capitán de Guerra de Maracapana. En 1552 emprende la expedición hacia El Tocuyo y es uno de los fundadores de Nueva Segovia de Barquisimeto, en la actual Venezuela. Regresa de nuevo a Quito, ciudad donde residió entre 1562 y 1564. El 15 de septiembre de 1563 presenta la información sobre sus méritos y servicios ante el alcalde de Zamora (AGI, Patronato, Legajo 156, Ramo 4º). El 7 de febrero de 1564 el cabildo de Zamora escribe una recomendación en favor de su procurador Diego Hernández de Serpa (AGI, Quito, 18, N. 19) , y el 24 de septiembre de 1564 el procurador Diego Hernández de Serpa, en nombre de Zamora, solicita una merced para la iglesia de esa ciudad (AGI, Quito, 18, N. 24). Al año siguiente viaja desde Cartagena de Indias a Madrid donde hace presentación de sus méritos y servicios. En 1568 recibe la Capitulación para la conquista de la Nueva Andalucía (Venezuela). Un año después parte de Sanlúcar de Barrameda en España con una flota para la conquista de los territorios del oriente venezolano. Llega a Venezuela y en 1569 funda Cumaná. Organiza la conquista de Guayana y El Dorado y muere el 10 de mayo de 1570, en la Quebrada de Hoces, combatiendo contra los indígenas cumanagotos y chacopatas (Ojer y Subero, 53-99). Como señala Tejedor: "Sorprende ciertamente la personalidad de este conquistador, puesto que con su gran actividad y movilidad, desde el modesto-y productivo- 
trabajo de carpintero en Cubagua, llegó a encumbrarse hasta ser nombrado Capitán de la conquista de Guayana y Gobernador de la Provincia de Cumaná" (77).

\section{La epístola poética}

Los actos y hazañas valerosas está precedido por una epístola de 94 versos endecasílabos dedicada a don Diego de Zúñiga y de Avellaneda, conde de Miranda. La misiva intenta captar la benevolencia del destinatario y, al mismo tiempo, apela a la fórmula de la falsa humildad. Por otro lado, la epístola destaca la relevancia del tema a tratar, una función que proviene de la fórmula retórica de la amplificación y sirve para ensalzar el asunto del poema. Por ello Pedro de la Cadena resalte las hazañas del protagonista, pues las acciones del capitán Diego Hernández de Serpa convierten al poema en modelo de literatura heroica. La epístola combina en su estructura el estilo de la misiva y el de la dedicatoria. El tono solemne que emplea el autor constituye una convención literaria de este género y se debe, además, a la importancia social del destinatario, que exige el uso estricto de los protocolos de tratamiento social de la época. La invocación a las Musas se sustituye por una dedicatoria al Conde de Miranda, que se hace desde el tópico de la humildad. La dedicatoria sigue la fórmula bipartita: "sujeto heroico, encomio de las hazañas" (Lara 407) y aparece seguida del tópico de la falsa humildad, evidente en este pasaje:

Príncipe esclarecido y excelente, en quien está el valor por propia esencia, y la virtud en su extremo alteza, a Vos que a lo perfecto dais renombre

con los heroicos hechos y gran fama del saber, fortaleza, gracia, y modo con que sois luz y Sol de nuestros tiempos y eclipsáis la grandeza a los pasados. A Vos, señor, mi pluma pide esfuerzo,

pide prudencia, estilo y dulce traza, para os atribuir lo que aquí canto y para cantar Victorias y Virtudes 
y la vida y honor y buena suerte

de un vasallo vuestro, al cual entre otros

merece ser señor, por ser él vuestro

y haber él en tal dicha habido fama

desde su juventud en aventuras,

que como capitán se ha señalado

en el mar océano y nuevo mundo (Ojer y Subero 174-76).

\section{El introito: épica y modelos literarios}

Después de la epístola figura el introito donde encontramos la proposición del argumento. El introito sigue un modelo positivo y describe de forma explícita el tema: cantar las hazañas de Diego Hernández de Serpa. El autor reconoce en la prótasis el pasado del género épico, en especial aquellos poemas que abordan un presente inmediato:

Canta con voz suave y sonorosa ¡oh fama! Aquellos hechos valerosos del capitán Diego Hernández de la Serpa, con la también su dicha y sus virtudes,

y su heroico ánimo e intento en que siempre ensalzó su honor y estado con ensalzar la fe y real servicio a costa de su sangre, haber y vida, dándose él mismo a sí inmortal corona, [...]

y en tanto que tú cuentas, fama noble, $[\ldots]$

los casos de español tan estimado, me deja a mí llorar entre españoles el gran descuido y dañado olvido que tienen los ingenios más notables en no solemnizar las maravillas (Ojer y Subero 184).

Despliega así una poética positiva, que se define a sí misma; por medio de ella el poeta traza los límites de su canto. En el esquema del introito coexisten dos niveles. Primero, en el plano historicista se 
rechaza la época pasada, ya que el poeta decide elogiar sólo las acciones recientemente ocurridas. Por otro lado, en el nivel literario imita los modelos medievales y a la vez crea un espacio propio para hacer oír su voz lírica. La proposición incorpora en el ritual introductorio el vocablo cantar. La alusión a la épica clásica que el autor hace en su texto es una adopción, en la prótasis, de las convenciones del género literario, lo cual implica la afirmación de la voz poética que habla desde un presente inmediato. El verbo cantar se utiliza en el presente porque se refiere a los acontecimientos que han transcurrido recientemente y de esta manera el autor cumple con la norma de la cercanía temporal. Pedro de la Cadena insiste en que el argumento de su poema es histórico y pasa a cantar las empresas gloriosas de Diego Hernández de Serpa. La declaración inicial del canto sigue el modelo de individualización del héroe bélico en la figura del protagonista y aparece definido por los atributos de valor, heroísmo y honor (García Soto 52). La proposición sigue la estructura metafórica del modelo de Virgilio porque la imitación del canto a las armas aparece modificado desde una visión que subordina los motivos clásicos paganos a la cristianización de la épica (Davis 23-26). En el poema no aparece una invocación directa a las Musas, sino a la Fama; ésta se complementa con el tópico del empequeñecimiento que sirve como formula de la falsa modestia.

\section{Épica imperio: el ideal conquistador}

Siguiendo el modelo de Juan de Mena en el Laberinto de Fortuna (1446), en Los actos y hazañas valerosas aparece el motivo de "salvar la memoria"; es decir, la necesidad de rememorar las hazañas a través de la poesía, la idea de la poesía en función de recordar el pasado. Fernán Pérez de Guzmán, en Loores de los claros varones de España (1452), defendió esta función de la poesía: lamenta el olvido al que han sido relegados los hechos heroicos debido a la falta de poetas que inmortalicen las hazañas pasadas. Siguiendo estos modelos literarios, Pedro de la Cadena intenta rescatar del olvido, por medio de la poesía, las hazañas de Diego Hernández de Serpa. Logra así incluir la verdad histórica en el poema y cumplir con el tópico de la poesía como vehículo de inmortalización. El introito guarda la norma épica de inicio llamada 
“delimitación monumental" (Genette 164), que abarca una variedad extensa de temas. De ahí la mención del motivo Urbs antiqua fuit que recuerda las conquistas de México y Perú, resaltando la grandeza de las acciones de los soldados españoles. Este panorama sirve para situar la vida del protagonista en el contexto de las victorias del imperio español:

de la virtud de fuertes castellanos, sabiendo que hoy el mundo está en su mano, y que entre las naciones son la prima, por ser de Dios sus siervos regalados a quien ha concedido grandes triunfos

desde oriente a poniente, y un norte a otro, domando tanto reinos y naciones, hasta rendir los hijos de Jafet en este nuevo mundo donde habitan, donde con menos de doscientos hombres,

en el Perú, en tres reencuentros grandes que con los naturales se ofrecieron, en tiempos y provincias muy diversas, ganaron grandes reinos y naciones, $\mathrm{y}$ en un reencuentro de estos sujetaron

más de un millón de gente bien armada.

Pues en el gran México quién tendrá memoria que pueda numerar las millaradas de escuadrones de gentes y ciudades que sujetaron armas castellanas

con muy poquito número de gentes. Pues en las indias e islas meridianas, quién bastará contar lo que hicieron, y lo mucho que hoy día se señalan, pues en las partes claras de levante,

en Francia, Italia, Flandes y Alemania ¡Cuántos reyes y reinos han domado! Y en esa África, y Asia, y Berbería, y en la navegación de todas partes, ¡quién bastará contar sus grandes hechos (Ojer y Subero 187). 
La idea central del pasaje es poner de manifiesto la magnitud de las victorias de las armas españolas en los territorios de América, África, Asia y Europa. Pedro de la Cadena presenta una cartografía poética del imperio español para universalizar el tema de la obra; este recurso sirve de contexto a las actividades del protagonista, muy de acuerdo con el sentido encomiástico de la obra. El autor ubica la enunciación del poema en los conquistadores españoles, y silencia a los indígenas quienes sólo aparecen de forma secundaria en la narración sobre los aztecas y los incas. La segunda parte del introito cierra con el motivo de la limitación humana porque insiste en la necesidad de la escritura como ayuda a la preservación poética de los hechos, pero subordinada a la idea de la justicia y sabiduría divinas. En la parte final del introito, el autor confiesa que la magnitud de las hazañas de los soldados españoles en America, África, Asia y Europa impide la creación de una obra poética representativa de estos eventos y restringe el tema del poema a las aventuras militares del protagonista.

En la composición, Pedro de la Cadena logra presentar las acciones del capitán Serpa como hazañas dignas de un personaje heroico, y, además, sienta las bases del tono encomiástico predominante en el poema. Por otro lado, el texto también cumple una función pragmática: el servir de apoyo al protagonista en su reclamación de bienes y privilegios por los servicios prestados a la corona. El poema igualmente exhibe uno de los rasgos de la épica colonial: la inclusión en la obra literaria de elementos sacados de la realidad porque el autor utiliza como fuente inmediata las relaciones de méritos y servicios de Diego Hernández de Serpa, consultadas entre 1563 y 1564. Este predominio del realismo en la ficción, característico de los poemas épicos americanos, es una muestra de las relaciones discursivas entre la historiografía y la literatura en los textos sobre la conquista de América. A la vez, confirma el pragmatismo que prevalece en la poesía épica, la cual cumple la misma función de servicio de las crónicas, en este caso apoyar las reclamaciones que hace el capitán Serpa por los servicios prestados a la Corona española. Esta función mediada que desempeña el poema permite entender el uso de un lenguaje encomiástico, donde la hipérbole es un elemento retórico principal del lenguaje poético: “y quisiera decir que sóis la cima/de la caballería 
cortesana, / y digno de entrar en la superna corte / pues la inmortalidad de vos celebra" (Ojer y Subero 178-80). Este poema se puede considerar como un memorial poético de encargo, ya que es una reescritura encomiástica de las relaciones que Diego Hernández de Serpa presenta ante la Corte. Sin embargo, el poema ofrece varias adiciones importantes, entre ellas las admoniciones morales y la inclusión de detalles adicionales sobre la biografía del protagonista.

Los actos y hazañas valerosas es el primer poema épico dedicado al territorio de la Nueva Andalucía, hoy Venezuela, porque antecede a las Elegías de varones ilustres de Indias de Juan de Castellanos (1a. parte, 1589), texto también escrito inicialmente en prosa (Restrepo 29-71). Entre las características del texto de Pedro de la Cadena está la historicidad empleada en la representación de los hechos, pues se privilegian los datos informativos provenientes de las relaciones de méritos y servicios del protagonista. Es decir, el modelo historiográfico adquiere una mayor relevancia frente al poético. Este elemento constituye otro punto de convergencia con la épica medieval. Por otra parte, la contribución del autor a la renovación del modelo épico se hace evidente en el repertorio de tropos y motivos retóricos utilizados en la elaboración del poema. Estos incorporan la nueva realidad americana a la tradición poética española, en especial, la inclusión de vocablos de las lenguas indígenas y de topónimos como Uyapari, Cubagua, Chalcoma, Maracapana, Guayana y Tocuyo para referirse al territorio venezolano.

La estructura de la composición se basa en un esquema bimembre, que privilegia una lectura donde la historia se poetiza. También el modelo virgiliano aparece revisado por la visión del héroe cristiano, quien aquí logra su ascenso social a través de la búsqueda de la fama de acuerdo al ideal del conquistador español. La interpretación que hace el poeta representa una idealización de los hechos históricos, pues ocasionalmente se altera la historia en función de la verdad poética. Por ejemplo, en el acto VII se narra la participación de Hernández de Serpa en la guerra contra los caribes, pero no existe documento que confirme este dato. La obra de Pedro de la Cadena muestra la capacidad de la épica para elaborar ficciones con una función ideológica (Quint 103) al promover el relato de una hazaña para encubrir otros aspectos de mayor importancia en este caso, la 
violencia de la conquista. Por ello el poema sirve de pretexto para hablar de la conquista como una acción heroica. La composición igualmente representa una tentativa de crear una ficción alternativa al discurso de la historia; por ejemplo, presenta a Diego Hernández de Serpa como un héroe importante, aunque los testimonios históricos de la época nunca lo mencionan en un rol destacado. En este sentido, el poema también participa en la creación del "mito de los hombres excepcionales" (Restall 1-26), para así elevar la importancia del protagonista.

Como corresponde a la épica de los vencedores, denominada por Quint "tradición de la dominación imperial" (9-10), Los actos y hazañas valerosas sigue un desarrollo lineal teleológico. Por eso la narración comienza con los orígenes familiares del héroe en España, continúa con las expediciones por el territorio venezolano y culmina con las batallas contra los indígenas y africanos en el Acto XVII. Las fórmulas del discurso poético presentan una verdad que pretende sustituir la historia oficial y controlar el discurso de la historia. La renovación en la forma de representar la realidad es otra de las transformaciones del género épico en tierras americanas; por medio de esta innovación también se trae al tablero crítico el problema de la constitución de la verdad en la obra poética. Este es un elemento vinculado al hecho histórico de la conquista de América porque la forma poética sirve para adornar y justificar las expediciones conquistadoras desde el punto de vista literario. De esta manera el autor intenta embellecer estética y moralmente la participación de Diego Hernández de Serpa en la conquista de Venezuela. En la ejecución de este cometido el ornato desempeña un papel fundamental; a éste se subordina la organización del poema y la exposición del tema tratado, que imita un orden temporal similar a los acontecimientos históricos recreados en la obra. Este modelo de historicidad es también un recurso poético derivado de la tradición literaria medieval, renovado en los poemas americanos.

El poema de Pedro de la Cadena no sólo imita modelos historiográficos y literarios medievales; también, por medio del título, establece un vínculo entre la composición y la retórica jurídica. El título Actos y hazañas pretende adjudicar al texto poético la autoridad del discurso jurídico y de ese modo legitimar el contenido del poema al emplear una estrategia retórica que busca atraer una mayor atención 
y reconocimiento para la obra. La vinculación del poema con el discurso jurídico implica que el autor atribuye a su obra un carácter de autenticidad que rebasa la verdad de las fórmulas historiográficas; su texto, en última instancia, está fundamentado en la autoridad del derecho y en la fuerza material de la burocracia imperial. Entre las nuevas posibilidades que ofrece el discurso legal a la poesía épica se encuentra la función de servir de apoyo a las reclamaciones de derechos y privilegios de aquellos conquistadores que se sentían olvidados por la corona. Una función que también se evidencia en los poemas épicos de la conquista de México (Mazzotti 147-49; PullésLinares 79-102). El poema de Pedro de la Cadena fue escrito para avalar estéticamente las relaciones de méritos y servicios presentadas ante la Corte por el protagonista; tanto la probanza como el poema tuvieron un resultado positivo: Felipe II le concedió a Diego Hernández de Serpa la Capitulación para la conquista de la Nueva Andalucía en 1568. En ese sentido, Los actos y hazañas valerosas, a pesar de ser un texto poco estudiado, pone de manifiesto la importancia y prestigio social de la poesía épica en el siglo XVI. 